\title{
Hematopoietic Commitment during Embryonic Stem Cell Differentiation in Culture
}

\author{
GORDON KELLER, ${ }^{1 *}$ MARION KENNEDY,${ }^{1}$ THALIA PAPAYANNOPOULOU, ${ }^{2}$ \\ AND MICHAEL V. WILES ${ }^{3}$ \\ The National Jewish Center, 1400 Jackson Street, Denver, Colorado $80206^{1}$ Department of Medicine, \\ Division of Hematology, School of Medicine, University of Washington, Seattle, Washington 989152; \\ and The Basel Institute for Immunology, Basel CH4005, Switzerland ${ }^{3}$
}

Received 14 August 1992/Returned for modification 1 October 1992/Accepted 17 October 1992

\begin{abstract}
We report that embryonic stem cells efficiently undergo differentiation in vitro to mesoderm and hematopoietic cells and that this in vitro system recapitulates days 6.5 to 7.5 of mouse hematopoietic development. Embryonic stem cells differentiated as embryoid bodies (EBs) develop erythroid precursors by day 4 of differentiation, and by day 6 , more than $85 \%$ of EBs contain such cells. A comparative reverse transcriptase-mediated polymerase chain reaction profile of marker genes for primitive endoderm (collagen $\alpha$ IV) and mesoderm (Brachyury) indicates that both cell types are present in the developing EBs as well in normal embryos prior to the onset of hematopoiesis. GATA-1, GATA-3, and vav are expressed in both the EBs and embryos just prior to and/or during the early onset of hematopoiesis, indicating that they could play a role in the early stages of hematopoietic development both in vivo and in vitro. The initial stages of hematopoietic development within the EBs occur in the absence of added growth factors and are not significantly influenced by the addition of a broad spectrum of factors, including interleukin-3 (IL-3), IL-1, IL-6, IL-11, erythropoietin, and Kit ligand. At days 10 and 14 of differentiation, EB hematopoiesis is significantly enhanced by the addition of both Kit ligand and IL-11 to the cultures. Kinetic analysis indicates that hematopoietic precursors develop within the EBs in an ordered pattern. Precursors of the primitive erythroid lineage appear first, approximately $24 \mathrm{~h}$ before precursors of the macrophage and definitive erythroid lineages. Bipotential neutrophil/macrophage and multilineage precursors appear next, and precursors of the mast cell lineage develop last. The kinetics of precursor development, as well as the growth factor responsiveness of these early cells, is similar to that found in the yolk sac and early fetal liver, indicating that the onset of hematopoiesis within the EBs parallels that found in the embryo.
\end{abstract}

The hematopoietic system of the mouse is established early during embryogenesis from the extraembryonic mesoderm of the yolk sac $(26,43)$. The precise period of mesodermal commitment to the hematopoietic lineage is difficult to determine, since the first visible signs of hematopoietic activity (7.5 to 8.0 days of gestation) are the yolk sac blood islands, which consist of cells already committed to the erythroid lineage $(26,43,67)$. The precursors of these erythroid cells, which likely represent the earliest embryonic hematopoietic cells, have developed prior to the onset of blood island hematopoiesis. As such, the stages of commitment from mesoderm to the formation of the first hematopoietic cells must occur shortly after implantation, a developmental stage which is difficult to access.

Mouse embryonic and fetal hematopoietic development is characterized by rapid dramatic changes. For instance, visual inspection of the egg cylinder/yolk sac at 7.5 days of gestation fails to show any signs of hematopoiesis, whereas by day 8 , numerous blood islands are easily detected. The yolk sac remains the primary hematopoietic organ until approximately day 12 of gestation, producing primitive nucleated erythroid cells as well as some macrophages $(9,15)$. Beyond this stage of development, yolk sac hematopoiesis declines and the fetal liver becomes the predominant hematopoietic organ for the remainder of fetal life (43). The mechanisms involved in the development of this primary hematopoietic system as well as those which regulate the

\footnotetext{
${ }^{*}$ Corresponding author.
}

rapid changes throughout ontogeny are not known. With respect to known growth factors, much of our knowledge stems from studies on adult marrow and to a lesser extent on fetal liver. Evidence exists which suggests that some hematopoietic growth factors are produced during embryonic and fetal development $(4,33,34,38,41)$. However, these analyses have been carried out moderately late in embryogenesis, and thus the role of these factors in the establishment and growth of the most primitive embryonic hematopoietic cells is not known.

At the molecular level, a number of different genes have been identified whose patterns of expression suggest that they are involved in the earliest stages of hematopoietic commitment. One such class of genes, the GATA family of genes which encode zinc finger transcription factors, are expressed in hematopoietic cells very early in development $(59,71)$. Inactivation of GATA-1 through homologous recombination in embryonic stem (ES) cells results in their inability to generate erythroid cells in vivo and in vitro, thus demonstrating that this gene plays an essential role in erythroid development $(52,57)$. The precise role of the other GATA genes remains to be determined. c-myb, which encodes a DNA-binding protein, is expressed at the precursor stage of development in many hematopoietic lineages and then appears to be downregulated as the cells mature (40). Recent studies involving the inactivation of the c-myb gene in ES cells have indicated that this gene is essential for fetal but not embryonic (yolk sac) hematopoiesis (45). Another class of transcription factors that could play a major role in the development of the early hematopoietic system are those 
which share a common helix-loop-helix motif $(6,7)$. Members of this family are thought to play a pivotal role in differentiation and development, and at least one, SCL, is expressed abundantly in hematopoietic cells $(6,7)$. Finally, the hematopoietic cell-restricted pattern of expression of the $v a v$ proto-oncogene, and in particular its expression in the fetal liver, suggests that it could be involved in early hematopoietic development $(1,36)$.

Many studies aimed at defining the molecular events involved in the establishment of the hematopoietic system as well as those aimed at examining the role of the various growth factors in the expansion of the early populations are hampered by the inaccessibility of the early embryo as well as by the limited amount of tissue available at this stage of development. To overcome this problem, a number of different groups have focused on developing in vitro model systems that would accurately and reproducibly duplicate the events involved in establishing the primary hematopoietic system in vivo $(10,17,39,56,61)$. These model systems are all based on the ability of ES cells to spontaneously differentiate and generate hematopoietic cells in culture. The advantages of such a model system are severalfold. First, one has access to the cells at all stages of differentiation, making it possible to manipulate the system as it develops. Second, an in vitro model system based on ES cells will enable one to study the function of a broad spectrum of genes through their inactivation by homologous recombination without encountering the problems inherent to an in vivo system; namely, embryonic lethalities. To carry out such analysis in culture, both alleles of a gene must be inactivated. A recent report by Mortensen et al. (44) indicates that this can be accomplished by simply culturing ES cells with a single inactivated allele in elevated levels of the selection drug. Combining this technique with an efficient in vitro model system will provide a unique approach to identifying genes involved in early hematopoietic development.

Previous studies have demonstrated that ES cells will differentiate in culture and generate multiple hematopoietic lineages $(10,17,39,56,61)$. However, in most of these studies, the extent of hematopoietic development has been limited and variable, and the exact kinetics of hematopoietic differentiation has been unpredictable or poorly defined. For an ES-based in vitro model system to be useful as a tool in the dissection of developmental hematopoiesis, it must reproducibly and efficiently develop hematopoietic cells with a well-defined kinetic pattern. In addition, hematopoietic development within these cultures should follow a sequence of events similar to that involved in the establishment of the hematopoietic system in the normal embryo.

In this report, we demonstrate that ES cells will efficiently generate hematopoietic cells in culture with a reproducible kinetic pattern. In addition, we examine a profile of genes expressed in both embryoid bodies (EBs) and the embryo which indicates that a developmental program, involving a transition from primitive ectoderm to mesoderm to hematopoietic cells in culture, parallels the sequence of events found in the mouse embryo. Finally, we show that the growth factor responsiveness of the ES-derived hematopoietic cells, as well as the kinetics of development of individual lineages in these cultures, is similar to that observed in the early yolk sac of the embryo, suggesting that the events ongoing in vitro reflect those taking place in vivo.

\section{MATERIALS AND METHODS}

Cells. The 129/Sv-derived ES line cell CCE (55) was adapted to grow in the presence of leukemia-inhibitory factor (LIF) without feeder cells. These cells were maintained in the absence of feeders for a maximum 15 passages. Undifferentiated ES cells were maintained on gelatinized flasks in Dulbecco's modified Eagle medium supplemented with LIF, $15 \%$ fetal calf serum (FCS), and $1.5 \times 10^{-4} \mathrm{M}$ monothioglycerol. Under these conditions, more than $95 \%$ of the cell population remained undifferentiated, as determined by visual inspection under phase-contrast microscopy. Batches of serum for this purpose were chosen on the basis of their ability to support ES cells in an undifferentiated state. Approximately $75 \%$ of all serum batches tested were acceptable. Two days prior to the initiation of differentiation, cells were passaged into Iscove's modified Dulbecco's medium (IMDM) supplemented with the same components.

Growth factors. LIF was obtained as a conditioned medium from a LIF-transfected $\mathrm{CHO}$ cell line, available as a gift from Genetics Institute Inc., Cambridge, Mass. Recombinant Kit ligand (KL) was provided by David Cosman (Immunex), and recombinant macrophage colony-stimulating factor (M-CSF), erythropoietin (Epo), and interleukin-11 (IL-11) were obtained from Genetics Institute. Recombinant IL-3 was obtained from medium conditioned by X63 Ag8-653 myeloma cells transfected with a vector expressing IL-3 (35). Recombinant IL-1 $\alpha$ (human) was provided by Peter Lomedico, Hoffmann-La Roche, Nutley, N.J. Recombinant platelet-derived growth factor, BB (human), basic fibroblast growth factor (human), insulin-like growth factor I (human), and IL-6 (mouse) were purchased from Upstate Biotechnology, Inc. (Lake Placid, N.Y. USA).

Difierentiation of ES cells. For the differentiation cultures, the cells were dissociated by trypsinization and cultured in $1.0 \%$ methylcellulose in IMDM with either $15 \%$ plasmaderived serum (PDS; Cocalico Biologicals, Reamstown, Pa.) or $15 \% \mathrm{FCS}, 300 \mu \mathrm{g}$ of iron-saturated transferrin, and a final concentration of $4.5 \times 10^{-4} \mathrm{M}$ MTG $(60,61)$. Between 300 and 1,500 CCE ES cells were plated in a final volume of 1.5 $\mathrm{ml}$ of this mixture in 35-mm-diameter bacterial-grade dishes. In some differentiation experiments, the methylcellulose medium was further supplemented with insulin (Sigma catalog no. I-6634) at $10 \mu \mathrm{g} / \mathrm{ml}$, as this was found to increased the ES cell plating efficiency (data not shown). Cultures were maintained in a humidified environment with $5 \% \mathrm{CO}_{2}$ in air at a temperature of $37^{\circ} \mathrm{C}$. Serum batches for ES differentiation were tested for their ability to support efficient EB development, for their ability to support the development of hematopoietic precursors within the EBs, and for their ability to support the growth of hematopoietic precursors in the secondary methylcellulose cultures. For most of the replating studies, PDS rather than FCS was used, as EBs differentiated in it contained fewer ES cells than did those differentiated in FCS. In addition, the colonies derived from the earliest erythroid precursors developed much better in PDS than in FCS. Most batches of PDS were found to be acceptable.

Assay for myeloid precursors within the EBs. At various days of differentiation, the EBs were removed from the methylcellulose by dilution of the semisolid medium with excessive amount of IMDM. The cells within the EBs were dissociated by incubation $\left(1 \mathrm{~h}\right.$ at $\left.37^{\circ} \mathrm{C}\right)$ in a solution of $0.25 \%$ collagenase in phosphate-buffered saline supplemented with $20 \%$ FCS. Following this incubation, the cells were gently passed through a syringe with a 20-gauge needle. The 
TABLE 1. Oligonucleotide primers used for gene expression analysis by RT-PCR

\begin{tabular}{|c|c|c|c|c|c|c|}
\hline \multirow[b]{2}{*}{ Gene } & \multicolumn{2}{|c|}{ Size (bp) } & \multirow{2}{*}{$\begin{array}{c}\text { Annealing } \\
\text { temp } \\
\left({ }^{\circ} \mathrm{C}\right)\end{array}$} & \multirow[b]{2}{*}{5 ' sequence } & \multirow[b]{2}{*}{ 3' sequence } & \multirow[b]{2}{*}{ Positive control (reference) } \\
\hline & cDNA & $\begin{array}{c}\text { Genomic } \\
\text { DNA band }\end{array}$ & & & & \\
\hline Activin $\beta_{B}$ & 426 & 426 & 50 & 5'GTCAATTTGACGTGGTTTCC & 5'GCAAGAATGTGCTGATCAAC & ES cells (3) \\
\hline AFP & 410 & $\sim 1,400$ & 50 & 5'GCTCACACCAAAGCGTCAAC & 5'CCTGTGAACTCTGGTATCAG & Yolk sac, day 8.5 (19) \\
\hline$\beta \mathrm{H} 1$ & 265 & 1,053 & 55 & 5'AGTCCCCATGGAGTCAAAGA & 5'CTCAAGGAGACCTTTGCTCA & Yolk sac, day 8.5 (9) \\
\hline$\beta$ major globin & 578 & 1,296 & 55 & 5'CTGACAGATGCTCTCTTGGG & 5'CACAACCCCAGAAACAGACA & Fetal liver, day 14 \\
\hline Brachyury & 947 & $\gg 947$ & 50 & 5'TCCAGGTGCTATATATTGCC & 5'TGCTGCCTGTGAGTCATAAC & Embryo, day 8.5 (62) \\
\hline c-kit & 765 & 765 & 55 & 5'TGTCTCTCCAGTTTCCCTGC & 5'TTCAGGGACTCATGGGCTCA & Bone marrow \\
\hline Collagen a IV & 463 & 463 & 55 & 5'CAAGCATAGTGGTCCGAGTC & 5'AGGCAGGTCAAGTTCTAGCG & PYS cell line (49) \\
\hline$c-m y b$ & 681 & 681 & 55 & 5'TTCAAGGCCAGCATTCTTGC & 5'CCTCTAGGAGCTCATTTGTG & Concanavalin A-treated spleen (70) \\
\hline Epo & 409 & 851 & 50 & 5'ATGTCACTGCTGGTGCTGGA & 5'TGCTAGCCAATTCCTCCCAG & IW32 cells $(14)$ \\
\hline Epo receptor & 452 & 452 & 55 & 5'GGACACCTACTTGGTATTGG & 5'GACGTTGTAGGCTGGAGTCC & ES cells (28) \\
\hline GATA-1 & 581 & $581+$ smear & 55 & 5'ATGCCTGTAATCCCAGCACT & 5'TCATGGTGGTAGCTGGTAGC & Fetal liver, day 13 (59) \\
\hline GATA-3 & 532 & 532 & 50 & 5'CCTTAAAACTCTTGGCGTCC & 5'AGACACATGTCATCCCTGAG & Fetal thymus, day 18 (37) \\
\hline HPRT & 249 & $\sim 1,100$ & 50 & 5'CACAGGACTAGAACACCTGC & 5'GCTGGTGAAAAGGACCTCT & Housekeeping gene \\
\hline IL-3 & 288 & 545 & 50 & 5'TCAGACTTTAGGTGCTCTGC & 5'TCGTGGAAAGCCAAGGAGAA & WEHI 3.1 cell line $(69)$ \\
\hline IL-3 receptor & 920 & 920 & 50 & 5'GCAGACAAGCTTAGTTGTGG & 5'TCTTAACATGGAGGCCGTTC & Mast cells (32) \\
\hline KL & $\begin{array}{l}592 \\
508\end{array}$ & $\sim 1,500$ & 50 & 5'GACTGTGTGCTCTCTTCAAC & 5'CTTGCAAAACCTCCAGAGTC & Spleen cells $(72)$ \\
\hline M-CSF & 651 & $\gg 651$ & 55 & 5'CAGATCAAGGAAGACAACCG & 5'ATGGTACATCCACGCTGCGT & L929 L cells (8) \\
\hline SCL & 744 & 744 & 55 & 5'ATTGCACACACGGGATTCTG & 5'CATACAGTACGACACTGACG & Fetal liver, day 14 (6) \\
\hline c-vav & 604 & Smear & 50 & 5'GTATAACGTGGAGGTCAAGC & 5'GGAGGACTGGAGAAAATCAG & Fetal liver, day 14 (1) \\
\hline
\end{tabular}

EB-derived cells were counted and replated in the same conditions used for the primary cultures except that $10 \%$ rather than $15 \%$ PDS was used and a source of hematopoietic growth factors was included. Colonies of hematopoietic cells were scored following 7 to 8 days of incubation in the same environment used for the primary cultures.

RNA isolation and cDNA preparation from ES cells and embryos. Total RNA was isolated from various tissues and cells using the acid-guanidinium-phenol-chloroform protocol (13). The procedure was modified as follows: acid-guanidinium-phenol-chloroform extraction was conducted only once, and 5 to $10 \mu \mathrm{g}$ of RNase- and DNase-free glycogen was added to aid RNA precipitation. In all cases except for day 6.5 mouse egg cylinders, RNA preparations were subjected to a DNase digestion step before cDNA synthesis, thus eliminating any remaining genomic DNA.

Mouse embryos (129/Sv) were dissected free of decidua at various time points. Noon of the day the copulation plug was found was designated 0.5 days. Dissected embryos were also examined on a gross morphological level and appeared to resemble the published states for the times taken (5). In the case of the day 6.5 egg cylinder (primitive steak just forming), the Reichert's membrane was left intact. RNA was also isolated from the decidua at this stage. For the day $7.5 \mathrm{egg}$ cylinder (exocoelom formed, pre-blood island stage), the Reichert's membrane was removed. At 8.5 days of gestation (five- to six-somite stage), the yolk sac-exocoelom region was separated from the embryo portion. All polymerase chain reactions (PCRs) were conducted with cDNA derived from single embryos (i.e., not pools of embryos).

Oligo(dT)-primed cDNA was prepared from total RNA derived from $10^{3}$ to $10^{4}$ cells or single embryos, using mouse mammary leukemia virus (New England Biolabs) reverse transcriptase $(\mathrm{RT})$, in a reaction volume of $20 \mu \mathrm{l}$ under conditions recommended by the manufacturer. This cDNA was subsequently diluted up to $100 \mu \mathrm{l}$ with water and heated to $94^{\circ} \mathrm{C}$ for $2 \mathrm{~min}$ to inactivate the mouse mammary leukemia virus reverse transcriptase.

Semiquantitative RT-mediated PCR (RT-PCR). To com- pensate for variable RNA and cDNA yields, the amount of cDNA synthesized was calibrated by using the relative expression level of hypoxanthine phosphoribosyltransferase (HPRT) as a standard. Briefly, by using a series of dilutions of cDNA synthesized from known numbers of ES cells, PCR was performed with primers specific for HPRT (Table 1). Using the HPRT standard, all cDNA samples used in this study were then equalized to the equivalent of $\leq 60$ cells worth of ES cDNA per PCR, of which one-third was subjected to gel electrophoresis. cDNA balancing was by eye (ethidium bromide staining) or by quantitation of incorporated radiolabeled CTP into the specific PCR product. It should be noted that (i) cDNA balancing between samples was thought to be equal to or better than threefold and (ii) the cells worth value must be regarded as a very rough approximation of cells and cDNA used per reaction and is more likely to be an overestimation of the amount of material per PCR. As the genes of interest in this study are probably expressed in only a subset of cells, the amount of cDNA used per PCR, compared with HPRT, was increased by 5- to 10-fold.

PCRs involving ES-derived EB cDNAs were of $30 \mu \mathrm{l}$, using $1 \mathrm{U}$ of Taq polymerase (Perkin-Elmer Cetus, Norwalk, Conn.). PCR buffer was prepared as suggested by PerkinElmer Cetus but with the addition of $10 \mathrm{mM} \beta$-mercaptoethanol. EB PCRs were carried out by using a thermal cycler (PHC1; Techne Ltd., Cambridge, United Kingdom) with a regimen of $94^{\circ} \mathrm{C}$ for $0.6 \mathrm{~min}, 50$ or $55^{\circ} \mathrm{C}$ for $0.6 \mathrm{~min}$ (Table 1 ), and $72^{\circ} \mathrm{C}$ for $3 \mathrm{~min}$ for 30 cycles, followed by $72^{\circ} \mathrm{C}$ for 9.9 min. PCRs on embryo-derived cDNA were $15-\mu l$ reactions, using $0.5 \mathrm{U}$ of Taq polymerase and an AMS Biotechnology (Europe) Protocol thermal cycler, operating on a regimen of $94^{\circ} \mathrm{C}$ for $5 \mathrm{~s}, 50$ or $55^{\circ} \mathrm{C}$ for $15 \mathrm{~s}$ (see Table 1 for exact temperature used), and $72^{\circ} \mathrm{C}$ for $60 \mathrm{~s}$ for $30 \mathrm{cycles}$, followed by $72^{\circ} \mathrm{C}$ for $10 \mathrm{~min}$. For both ES-EB- and embryo-derived material, $8 \mu$ l of the resulting amplified material was gel electrophoresed rapidly in Tris-borate-EDTA buffer with $1.2 \%$ agarose.

For all sets of PCR primers, the annealing temperature and 
primer concentration used were determined empirically; the final oligonucleotide concentration was in the range of 1 to 2 $\mu \mathrm{g}$ per primer per $\mathrm{ml}$. Most sets of primers used were selected so as to be $3^{\prime}$ end biased and to span an intron. In a few cases, an intron was not found and the genomic and cDNA products were of similar size (Table 1). Whenever possible, PCR primers were optimized by using $1 \mathrm{ng}$ of genomic DNA per $30 \mu \mathrm{l}$ of PCR reaction mix (equivalent to approximately 330 copies of an autosomal gene). This also gives an indication of the relative efficiencies of the different primer sets. PCR product specificity was confirmed by the following criteria: RT-PCR signal was present in tissue and cells known to express the gene, the PCR product was absent in cells known not to express the gene, and the product was of the predicted size and gave a predicted pattern when digested with a frequently cutting restriction enzyme (data not shown). We believe that by using only 30 PCR amplification cycles, combined with the limited amounts of cDNA used per reaction, the possible problem of transcriptional gene leakage or illegitimate transcription should be alleviated; i.e., there should not be the scoring of a positive result on a physiologically insignificant amount of gene transcription $(11,12)$.

Globin analysis. Erythroid colonies were selectively picked from the methylcellulose cultures and pooled in $20 \mu \mathrm{l}$ of leucine-free medium in microcentrifuge tubes. One microliter of $\left[{ }^{3} \mathrm{H}\right]$ leucine (specific activity, $40 \mathrm{Ci} / \mathrm{mmol}$; New England Nuclear, Boston, Mass.) was added to the cells, and the tubes were then incubated at $37^{\circ} \mathrm{C}$ overnight. Following this incubation step, cell pellets were washed to remove unbound label and either used immediately or frozen in liquid nitrogen for later analysis. After the cell pellets were lysed in an appropriate lysing buffer (containing 3\% Nonidet $\mathrm{P}-40$ and $10 \% \beta$-mercaptoethanol in $8 \mathrm{M}$ urea), they were processed for isoelectric focusing in a LKB Multiphor apparatus according to previously described methodology (50, 54). After the completion of focusing, the gels were fixed in $20 \%$ trichloroacetic acid in $30 \%$ ethanol, treated with $\mathrm{En}^{3} \mathrm{Hance}$, rinsed, dried, and processed for autoradiography. Quantitation of globin chains was carried out by using fluorograms as described previously (50). In addition to erythroid colony lysates, whole blood lysates from 10-day C57BL/SJL embryos and from adult $129 / \mathrm{J}$ mice were treated in a similar manner and used as controls.

\section{RESULTS}

Kinetics of hematopoietic development within the EBs. The conditions used for ES differentiation were essentially as described before $(60,61)$, with the exception that higher amounts of serum $(15 \%)$ were included in the methylcellulose cultures. Increasing the amount of serum led to a higher plating efficiency of the ES cells ( 30 to $50 \%$ ) as well as to increased hematopoietic activity within the developing EBs (data not shown). For experiments involving the analysis of hematopoietic precursors (colony-forming cells [CFC]), ES cells were differentiated in the presence of PDS, as the resulting EBs were found to contain fewer undifferentiated ES cells compared with those differentiated in the presence of normal FCS. For gene expression studies, either 15\% PDS or $15 \%$ FCS was used, as there was no discernible difference in the expression patterns of the various genes examined (data not shown).

To determine the kinetics of hematopoietic precursor development in these cultures, EBs differentiated for various periods of time were harvested, and the cells were dissoci-
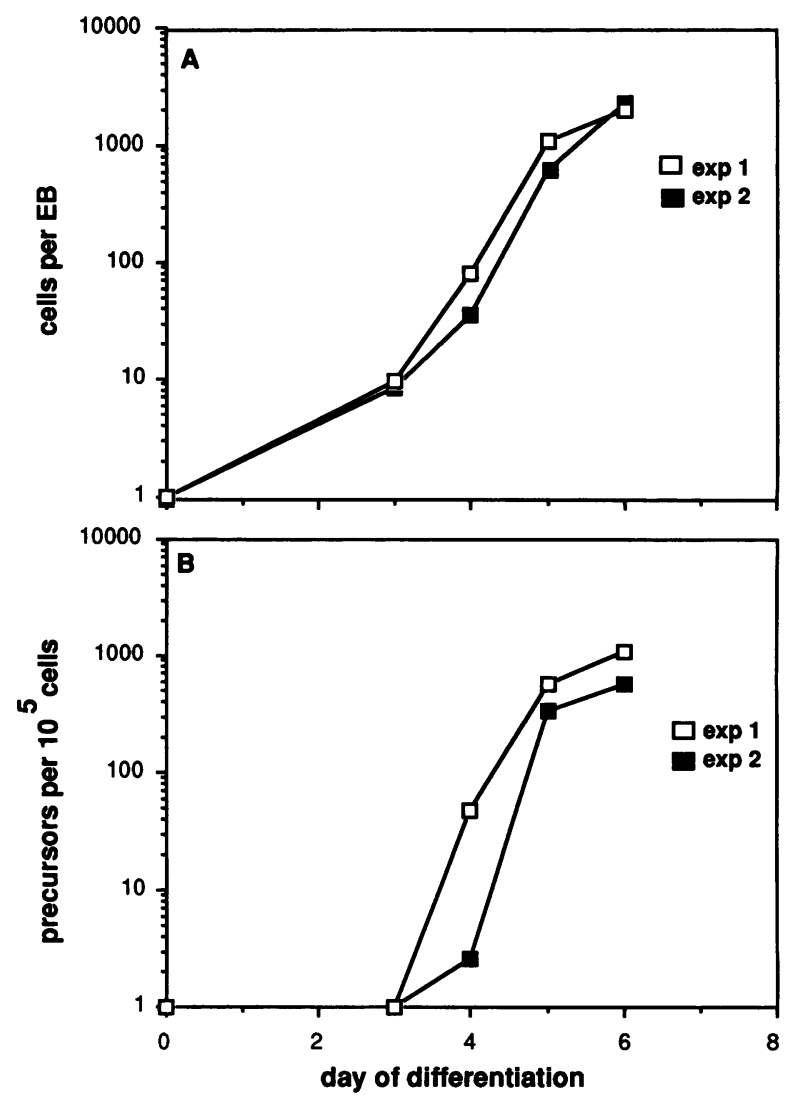

FIG. 1. Kinetics of hematopoietic development within the EBs. EBs were harvested at various days following the initiation of differentiation, and the cells were dissociated and replated into secondary cultures as described in Materials and Methods. Both the average EB size (A) and the precursor frequency within the EBs (B) were determined at the times indicated.

ated and then replated in secondary methylcellulose cultures containing Epo, IL-1, IL-3, and granulocyte macrophage colony-stimulating factor (GM-CSF) (a combination of factors that we have found to stimulate a broad spectrum of ES-derived CFC). Previous studies indicated that hematopoietic development occurred within the EBs in the absence of added growth factors, with the exception of those present in either FCS or PDS. Thus, to exclude the influence that factors might have on the kinetics of hematopoietic development, the EBs were differentiated in the presence of PDS $(15 \%)$ only. Sufficient numbers of cells required for replating could not be easily obtained before 3 days of growth and differentiation, at which time the average EB consisted of approximately 10 cells (Fig. 1A). In the two experiments shown in Fig. 1, the EB cellularity increased dramatically over the following $48 \mathrm{~h}$, to 40 to 80 cells per EB at day 4 and 600 to 1,000 cells per EB at day 5 of differentiation. The size increase over the next $24 \mathrm{~h}$ was more modest, with the day 6 EBs reaching an average size of 2,000 to 3,000 cells (Fig. 1A). Hematopoietic CFC were not detected in EBs differentiated for 3 days. Undifferentiated ES cells were still present at this time, as significant numbers of secondary EBs were detected in the replated cultures. Surprisingly, as early as day 4 of differentiation, low but variable numbers of CFC were found within the EBs in most experiments (Fig. 1B). By day 5 of differentiation, the frequency of CFCs increased dramatically in all experiments, and by day $6, \mathrm{CFC}$ routinely 
comprised as much as 0.5 to $1.0 \%$ of the total EB cell population. The number of undifferentiated ES cells able to generate secondary EBs decreased to almost undetectable levels by day 6 of differentiation. The large majority of the hematopoietic precursors detected at these early stages of differentiation were erythroid and grew in response to Epo, generating small colonies of cells that appear to represent the primitive erythroid population (see below). The kinetics of hematopoietic development described here are highly reproducible, being observed in virtually every experiment.

The kinetics studies described above were carried out with pools of EBs for each time point. To determine what proportion of individual EBs actually develop CFCs, single EBs differentiated for 6 days were picked and dissociated, and the cells were replated. More than $85 \%$ of randomly selected EBs were found to contain CFCs. However, approximately $10 \%$ of the EBs which began to develop in the initial cultures failed to grow and remained relatively small. These small EBs consistently failed to replate or replated very poorly. If these small EBs are excluded from the day 6 replating data, then virtually all medium to large EBs found at day 6 of differentiation contained precursor cells.

Gene expression during EB and embryo development. The rapid onset of hematopoietic development within EBs described above indicates that the molecular events involved in establishing the hematopoietic system occur rapidly in culture. In the next series of experiments, we took advantage of the reproducible and predictable pattern of hematopoeitic development within the EBs to analyze the expression pattern of a number of different genes during the pre- and early hematopoietic stages of development. The expression pattern from the EBs was compared with that found in the developing embryo. The RT-PCR data presented in Fig. 2 are limited to those genes of special interest; complete summaries of the RT-PCR analysis for both the EBs and embryos are presented in Tables 2 and 3.

Transition from primitive ectoderm to endoderm and mesoderm. ES cells are derived from the early embryo and appear to resemble the primitive ectoderm of the very early postimplantation mouse (21). Primitive ectoderm gives rise to mesoderm, from which the hematopoietic system is derived. The actual events involved in this commitment of the mesoderm to hematopoietic cells are not known but are thought to involve interactions between mesoderm and the extraembryonic endoderm of the yolk sac, which is itself derived from the primitive endoderm $(42,64)$. Thus, in the initial study, we analyzed the developing EBs for the presence of marker genes indicative of primitive ectoderm or ES cells (activin $\beta_{B}[3]$ ), mesoderm (Brachyury [29, 62]), primitive endoderm (collagen $\alpha$ IV [2]), and visceral endoderm (alpha-fetoprotein [AFP] $[19,20,30]$ ) to determine whether these various cell population develop in culture.

Activin $\beta_{B}$ was expressed in undifferentiated ES cells and then underwent a rapid downregulation to nearly undetectable levels at day 3 of differentiation, a finding similar to that reported by Albano et al. (3) (Fig. 2, Table 2). Low levels of collagen $\alpha$ IV RNA were detected $( \pm)$ in undifferentiated ES cells. Within the first $24 \mathrm{~h}$, there was a rapid increase in abundance $(+)$ of this RNA, with a further substantial increase between days 4 and 5 of differentiation $(+++)$, indicating that primitive endoderm developed rapidly within the EBs (Fig. 2, Table 2). Collagen $\alpha$ IV-specific RNA was found at high levels at all periods tested in the developing egg cylinder embryo (days 6.5 to 8.5 ) and in the day 6.5 day decidua (Table 3). In three independent experiments, Brachyury expression was not detectable in undifferentiated
ES cells (Fig. 2; Table 2). Within $72 \mathrm{~h}$ of differentiation, a low level $( \pm)$ of Brachyury-specific RNA was present in the EBs. The level of expression increased dramatically over the next $24 \mathrm{~h}$ (day 4 of differentiation) and then rapidly declined to undetectable levels by day 8 . Analysis of the normal embryo indicated that Brachyury RNA was already detectable in the 6.5-day-old egg cylinder. By day 8.5 of gestation, Brachyury expression was detected in the embryo proper but not in the yolk sac, an observation which essentially confirms and extends the findings of Wilkinson et al. (62). No Brachyury expression was detected in day 6.5 decidua. AFP was not expressed at significant levels within the EBs until after day 6 of differentiation, whereas it was readily detected in the day 6.5 egg cylinder. Together, these findings demonstrate that the ES cells begin to differentiate rapidly within the methylcellulose cultures, as demonstrated by the loss of activin $\beta_{B}$ expression. Moreover, they also indicate that endoderm, as defined by collagen $\alpha$ IV expression, and mesoderm, as defined by Brachyury expression, are both present within the EBs and the egg cylinder/embryo prior to and during the earliest stages of hematopoietic development.

Markers of hematopoiesis during EB and embryonic development. To further define the onset of hematopoiesis within the EBs and the normal embryo, we examined the expression profile of genes thought to be involved in the development of early hematopoietic cells. The first of these genes to be analyzed were two members of the GATA family. In three separate experiments, GATA-1-specific message was not detected in undifferentiated ES cells, a finding consistent with those of others $(28,57)$. It was detectable within the EBs by day 4 of differentiation. Its level of expression increased over the next $48 \mathrm{~h}$ and then remained constant throughout the course of the experiment (day 8). In the developing embryo, a strong $(++)$ GATA-1 signal was already detectable in the day 6.5 egg cylinder but not in the decidua. By 8.5 days of gestation, GATA-1 expression was limited to only the yolk sac portion, whereas after 9.5 days of gestation, it was also present within the embryo proper (data not shown). GATA-3 RNA was occasionally detected in undifferentiated ES cells $( \pm)$. By day 4 of differentiation, there was a considerable increase in abundance of GATA3-specific RNA, and this level remained constant throughout the time course of the experiment (Table 2). Surprisingly, GATA-3 was found to be present at relatively high levels in the day 6.5 decidua. Consequently, it is difficult to determine the true picture of GATA-3 expression in the developing embryo, as any decidua tissue attached to the embryo may give a false-positive result.

The expression of globin was next examined as a definitive marker of erythropoietic development. Embryonic ( $\beta \mathrm{H} 1)$ and adult ( $\beta$ major) globin RNAs could be detected reproducibly at 4 days of ES-EB differentiation. At this early stage of development, the $\beta H 1$ RNA appears to be more abundant $(+++)$ than $\beta$ major globin (+) RNA. (The genomic DNA control indicated that the efficiencies of these sets of primers were similar.) Signals derived from both types of globin continued to rise over the next 4 days of differentiation. In the egg cylinder, $\beta H 1$ RNA was not detectable at 6.5 days, indicating that this stage was still pre-erythropoietic. By 7.5 days, however, the egg cylinder contained substantial amounts of $\beta \mathrm{H} 1$, and by 8.5 days of gestation, high levels of $\beta H 1$ RNA were found in the embryo and in the yolk sac. Embryos were not analyzed for the presence of $\beta$ major globin because of the high probability of contamination from maternal blood.

As c-myb is expressed in most hematopoietic precursors, 

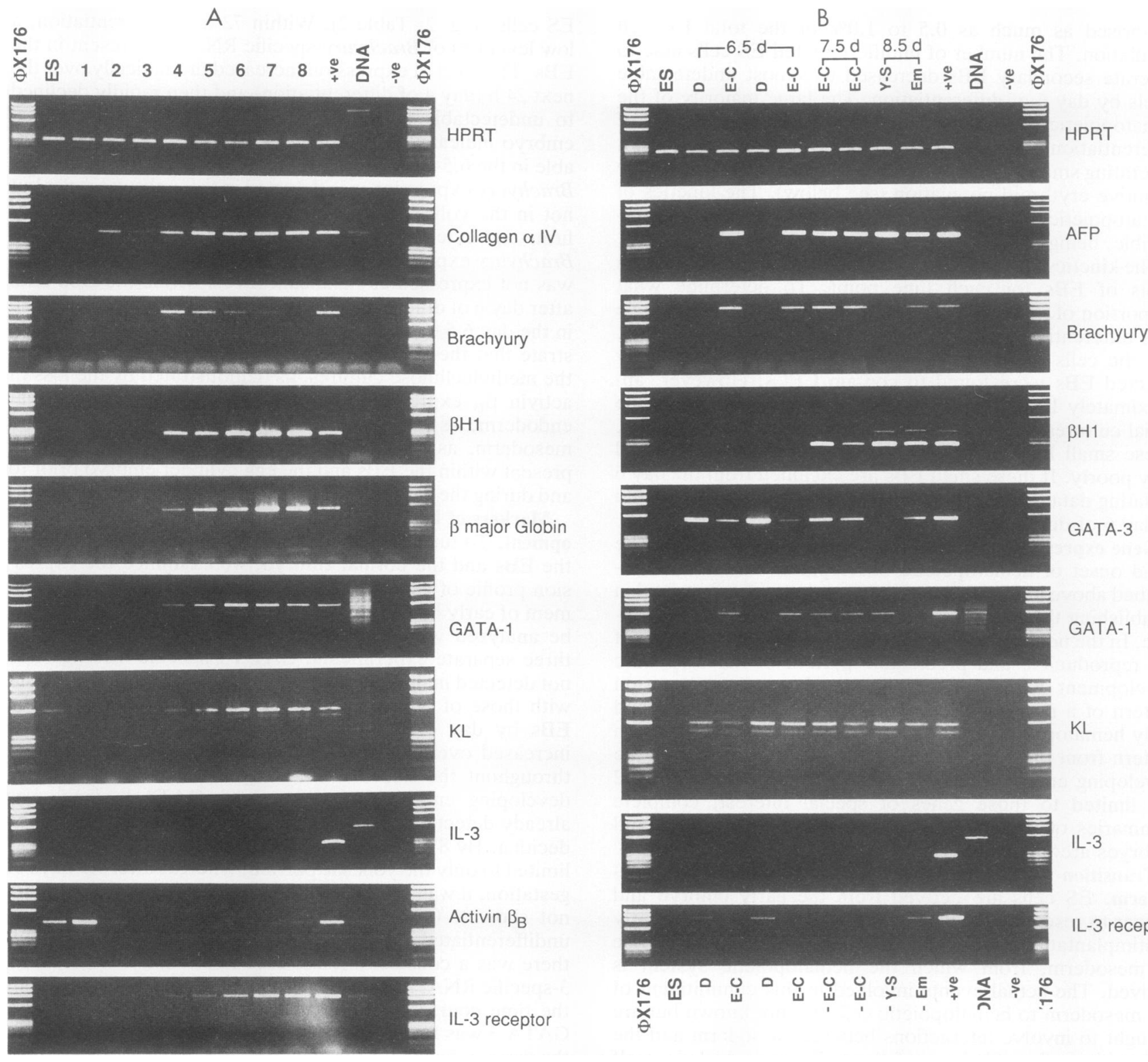

GATA-1

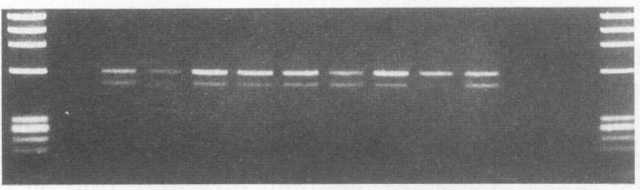

$\mathrm{KL}$
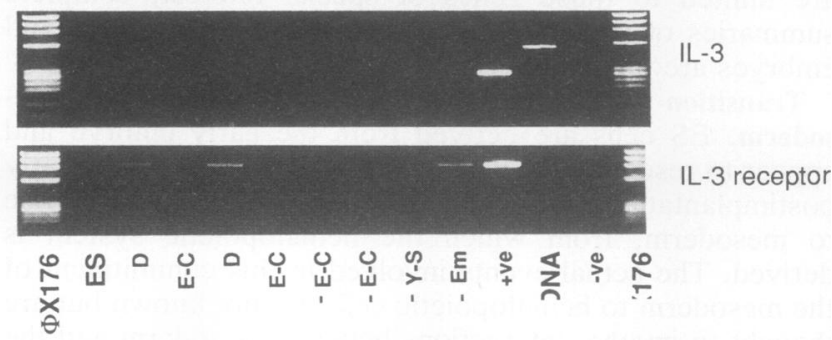

FIG. 2. Ethidium bromide-stained gels of the PCR amplification using various marker genes. After 30 cycles of amplification, samples were electrophoresed and photographed. First and last tracks are DNA size markers (HaeIII-digested $\phi X 176$ ). (A) ES, undifferentiated ES cells; 1 to 8, the number of days for which ES cells were differentiated. (B) ES, undifferentiated ES cells; D, decidua, E-C, egg cylinder, Y-S, yolk sac region; Em, embryo proper region. Numbers refer to the approximate ages of the egg cylinders/embryos used (see Materials and Methods). Negative controls (-ve) for all PCRs were no cDNA and, where possible, ES-derived cDNA. A positive control cDNA (+ve) and genomic DNA were run for all genes tested. The IL-3 PCR primers used here could readily detect 1 ng of genomic DNA per 30- $\mu$ l reaction. As such, they serve to show that there was no significant genomic DNA in any ES-EB-derived material used. Similarly, in embryo-derived cDNAs, there was no detectable genomic DNA except in one of the duplicate samples for the day 6.5 egg cylinder. Some \pm signals are not visible in these reproductions.

its presence could give an indication of the presence of nonerythroid hematopoietic lineages (40). As reported previously (18), c-myb was found to be expressed at low levels $( \pm)$ in undifferentiated ES cells. Expression was upregulated $(+)$ within $24 \mathrm{~h}$ of differentiation and increased further by day $4(++)$. Beyond this point in time, its level of expression remained constant (Table 2). SCL-specific RNA was not detected within the EBs until day 4 of differentiation. Its level increased between days 4 and 7 of development and then declined over the next $24 \mathrm{~h}$ (Table 2). vav was found to be expressed at low levels in undifferentiated ES cells. Its level of expression decreased within the first $24 \mathrm{~h}$ of differentiation and then began to increase over the next $24 \mathrm{~h}$, reaching maximum levels by day 4 (Table 2 ). Within the developing embryo, $v a v$-specific message was present in the decidua at day 6.5 of gestation but was not detectable in the egg cylinder at day 6.5 or 7.5 of gestation or in the yolk sac or whole embryo at day 8.5 of gestation.

The profile of gene expression reported here is consistent with our ES-EB kinetic studies, indicating that molecular 
TABLE 2. Complete summary of PCR data on ES-EBs time course, days 0 to 8

\begin{tabular}{|c|c|c|c|c|c|c|c|c|c|c|c|}
\hline \multirow{2}{*}{ Gene } & \multirow{2}{*}{ Cell no. ${ }^{a}$} & \multicolumn{9}{|c|}{ Signal detected after indicated days of differentiation ${ }^{b}$} & \multirow{2}{*}{$\begin{array}{l}\text { Specific genomic band } \\
\text { detectable with } 1 \mathrm{ng} \\
\text { of DNA }\end{array}$} \\
\hline & & 0 & 1 & 2 & 3 & 4 & 5 & 6 & 7 & 8 & \\
\hline HPRT & $\leq 20$ & ++ & ++ & ++ & ++ & ++ & ++ & ++ & ++ & ++ & \pm \\
\hline Collagen a IV & $\leq 100$ & \pm & + & ++ & + & ++ & +++ & +++ & +++ & ++ & + \\
\hline Brachyury & $\leq 200$ & - & - & - & \pm & +++ & ++ & + & \pm & - & $>>>^{c}$ \\
\hline BH1 & $\leq 100$ & - & - & - & - & +++ & +++ & $>+++$ & $>+++$ & $>+++$ & \pm \\
\hline$\beta$ major globin & $\leq 200$ & - & - & - & - & + & ++ & ++ & +++ & $>+++$ & \pm \\
\hline $\mathrm{AFP}^{d}$ & $\leq 100$ & - & - & - & - & - & - & \pm & \pm & + & + \\
\hline$c-m y b^{d}$ & $\leq 100$ & \pm & + & ++ & + & ++ & ++ & ++ & ++ & + & + \\
\hline$v a v^{e}$ & $\leq 200$ & \pm & - & \pm & \pm & + & + & + & + & + & $>>$ \\
\hline GATA-1 & $\leq 200$ & - & - & - & - & ++ & +++ & +++ & $++t$ & +++ & ++ smear \\
\hline GATA- $^{d}$ & $\leq 200$ & \pm & - & - & - & + & + & + & + & + & \pm \\
\hline $\mathrm{SCL}^{d}$ & $\leq 100$ & - & - & - & - & \pm & + & + & ++ & \pm & + \\
\hline Epo & $\leq 100$ & \pm & + & + & + & + & + & + & + & + & + \\
\hline $\mathrm{KL}^{e}$ & $\leq 100$ & + & \pm & - & \pm & + & ++ & +++ & +++ & ++ & $>>>$ \\
\hline $\mathrm{M}-\mathrm{CSF}^{d}$ & $\leq 200$ & - & - & - & - & - & - & \pm & \pm & \pm & $>>$ \\
\hline IL-3 & $\leq 200$ & - & - & - & - & - & - & - & - & - & + \\
\hline Activin $\beta_{B}$ & $\leq 200$ & $++^{f}$ & +++ & + & \pm & - & - & - & \pm & \pm & + \\
\hline Epo receptor $^{d}$ & $\leq 200$ & \pm & \pm & + & \pm & \pm & \pm & + & ++ & + & \pm \\
\hline c-kit & $\leq 200$ & + & - & \pm & \pm & + & + & ++ & +++ & ++ & \pm \\
\hline IL-3 receptor & $\leq 200$ & - & - & - & - & \pm & + & + & ++ & ++ & \pm \\
\hline
\end{tabular}

${ }^{a}$ A rough measure calibrated on RT-PCR versus HPRT, using known numbers of ES cells; designed to give an approximate measure of how many cells worth of cDNA was used. The cell number is, if anything, an overestimate of the amount of material (see Materials and Methods).

${ }^{b}$ After 30 cycles of amplification, samples were gel electrophoresed and photographed. Scoring (done by eye) is from \pm (trace signal) to +++ , (very strong signal). - , no signal.

$c>>>$, a large intron is present, giving a signal equal or greater than $1.4 \mathrm{~kb}$ with genomic DNA.

${ }^{d}$ Data not shown.

e KL primers were designed to detect two splice variants; the bands seen indicate that the mRNA is coding principally for the secreted version of KL.

$f$ The activin $\beta_{B}$ signal was found to be highly variable between different ES cell RNA preparations.

events which could be involved in establishing the hematopoietic system occur rapidly within the developing EBs and to some extent parallel that found in the embryo.

Analysis for hematopoietic factors and receptors present in the EBs and embryos. The hematopoietic system develops efficiently within the EBs in the absence of added growth factors with the exception of those present in the PDS or
FCS. As the EBs (and embryos) develop, an environment appropriate for hematopoietic development is obviously created. To determine whether known growth factors are produced within this environment, EBs differentiated for various periods of time were analyzed for the presence of RNA specific for the Epo, M-CSF, KL (Steel), and IL-3 genes. These genes were chosen because the factors that

TABLE 3. Complete summary of PCR data on embryos/egg cylinders, days 6.5 to 8.5 , and the 6.5-day decidua

\begin{tabular}{|c|c|c|c|c|c|c|c|c|c|c|c|}
\hline \multirow{3}{*}{ Gene } & \multirow{3}{*}{ Cell no. ${ }^{a}$} & \multirow{3}{*}{$\begin{array}{l}\text { Signal } \\
\text { detected } \\
\text { in } \mathrm{ES}^{b}\end{array}$} & \multicolumn{8}{|c|}{ Signal detected at embryo age (days) of ${ }^{b, c}$ : } & \multirow{3}{*}{$\begin{array}{l}\text { Specific genomic band } \\
\text { detectable with } 1 \mathrm{ng} \\
\text { of DNA }\end{array}$} \\
\hline & & & \multicolumn{2}{|c|}{6.5} & \multicolumn{2}{|c|}{6.5} & \multirow{2}{*}{$\begin{array}{l}7.5, \text { egg } \\
\text { cylinder }\end{array}$} & \multirow{2}{*}{$\begin{array}{l}7.5 \text {, egg } \\
\text { cylinder }\end{array}$} & \multicolumn{2}{|c|}{8.5} & \\
\hline & & & Decidua & $\begin{array}{c}\text { Egg } \\
\text { cylinder }\end{array}$ & Decidua & $\begin{array}{c}\text { Egg } \\
\text { cylinder }\end{array}$ & & & $\begin{array}{l}\text { Yolk } \\
\text { sac }\end{array}$ & Embryo & \\
\hline HPRT & $\leq 20$ & ++ & ++ & ++ & ++ & ++ & ++ & ++ & ++ & ++ & + \\
\hline Collagen a IV $^{d}$ & $\leq 200$ & + & $>+++$ & $>+++$ & $>+++$ & +++ & +++ & +++ & +++ & +++ & + \\
\hline AFP & $\leq 200$ & - & \pm & +++ & \pm & +++ & +++ & +++ & $>+++$ & +++ & \pm \\
\hline Brachyury & $\leq 200$ & - & - & ++ & - & ++ & ++ & ++ & - & + & + \\
\hline BH1 & $\leq 200$ & - & - & - & - & - & $>+++$ & ++ & $>+++$ & $>+++$ & + \\
\hline GATA-3 & $\leq 200$ & \pm & +++ & $++\infty$ & $>+++$ & + & ++ & ++ & + & +++ & \pm \\
\hline GATA-1 & $\leq 200$ & - & - & $++^{\infty}$ & - & ++ & ++ & ++ & ++ & - & Smear \\
\hline$v a v^{d}$ & $\leq 200$ & \pm & ++ & - & ++ & - & - & - & - & - & $>>>^{f}$ \\
\hline Epo & $\leq 200$ & \pm & + & $++^{\infty}$ & ++ & ++ & + & \pm & + & ++ & + \\
\hline $\mathbf{K L}^{\mathbf{g}}$ & $\leq 200$ & + & ++ & + & ++ & ++ & ++ & ++ & ++ & ++ & $>>>$ \\
\hline M-CSF ${ }^{d}$ & $\leq 200$ & - & \pm & \pm & + & \pm & \pm & - & - & \pm & $>>>$ \\
\hline IL-3 & $\leq 200$ & - & - & $-\infty$ & - & - & - & - & - & - & + \\
\hline c-kit & $\leq 200$ & \pm & + & $\pm^{\infty}$ & ++ & \pm & + & \pm & + & +++ & \pm \\
\hline IL-3 receptor & $\leq 200$ & - & + & - & + & - & - & - & - & + & \pm \\
\hline
\end{tabular}

a See Table 1, footnote $a$.

$b$ See Table 1 , footnote $b$.

$c$ See Materials and Methods for description of embryo stages.

${ }^{d}$ Data not shown.

$e \infty$, trace of genomic DNA in cDNA sample detected, possibly interfering with result.

$f$ See Table 1 , footnote $c$.

8 See Table 1, footnote $e$. 
they encode are known to be regulators of erythroid and macrophage development, the first two lineages to be detected within the EBs (see below) and the embryonic yolk sac.

$\mathrm{KL}$, which encodes the ligand for the c-kit receptor, undergoes a differential splicing event, and thus the PCR primers were designed to show both splicing variants appearing as bands of different sizes after gel electrophoresis (Fig. 2). We detected low levels of KL RNA in undifferentiated ES cells, confirming the result of Schmitt et al. (56). During the first $48 \mathrm{~h}$ of differentiation, the amount of KL-specific RNA fell to undetectable levels. A signal was again present after $72 \mathrm{~h}(+)$, increasing over time and reaching a comparatively high level $(+++)$ by day 6 of differentiation. A KL-specific RNA signal was readily detectable in 6.5- and 7.5-day egg cylinders as well as in the 6.5-day decidua. Both the yolk sac region and the developing embryo were positive for KL RNA at 8.5 days. The majority of the RNA detected in the EBs and the developing embryo appears to be that of the longer transcript, which is thought to be the secreted version of $\mathrm{KL} \mathrm{(22).} \mathrm{There} \mathrm{is} \mathrm{no} \mathrm{marked}$ change in the ratio of the splicing variants found in the EBs or embryos at various stages of development. The receptor for KL, c-kit, was also expressed in ES cells (+). Similarly to the pattern observed with $\mathrm{KL}$, the levels of c-kit expression declined soon after the initiation of differentiation and then began to increase, reaching readily detectable levels by day 6 of differentiation. In the embryo, c-kit was detected at 6.5 to 8.5 days of gestation, with the highest signal being present in the day 8.5 embryo proper.

As reported previously, trace levels of Epo RNA were detectable in undifferentiated ES cells (56). Within $24 \mathrm{~h}$ of differentiation, there was an increase in Epo-specific RNA to levels that remained constant through the 8-day time course of the experiment. Epo-specific RNA was also detected in egg cylinder and decidua at day 6.5 of gestation, in egg cylinder at day 7.5, and in the embryo and yolk sac at day 8.5. RNA specific for the Epo receptor was detectable $( \pm)$ in undifferentiated ES cells, a finding consistent with those of others $(28,56)$. There was a slight increase in the levels of Epo receptor expression during the first 6 days of EB differentiation. M-CSF RNA was not detected within the EBs during the first 5 days of differentiation, and only trace levels were present after this time (Table 2). Expression of c-fms, the gene which encodes the receptor for M-CSF, was not detected until day 6 of differentiation (not shown). Only trace levels of M-CSF RNA were found in the embryo between days 6.5 to 8.5 of gestation and in the decidua at 6.5 days.

An IL-3-specific message was not detected at any time during EB differentiation, nor was it detected in the developing embryo between days 6.5 and 8.5. However, RNA for the AIC2A IL-3 receptor $\left(\beta_{\text {IL3 }}\right)(27,32)$ was detected as early as day 4 of ES cell differentiation and reached plateau levels by day 7 of differentiation. This receptor was not, however, detectable until 8.5 days of embryonic development, and then it was found only in the embryo proper portion.

Influence of exogenous growth factors on EB differentiation. The results of the previous experiments indicated that hematopoiesis developed within the EB in the absence of added growth factors with the exception of those present in PDS. In the next experiment, various growth factors were added to the differentiation cultures to determine whether the extent of hematopoietic activity within the EBs could be influenced. The following factors were tested: Epo, M-CSF (CSF-1), IL-1 $\alpha$, IL-3, IL-6, IL-11, KL, platelet derived
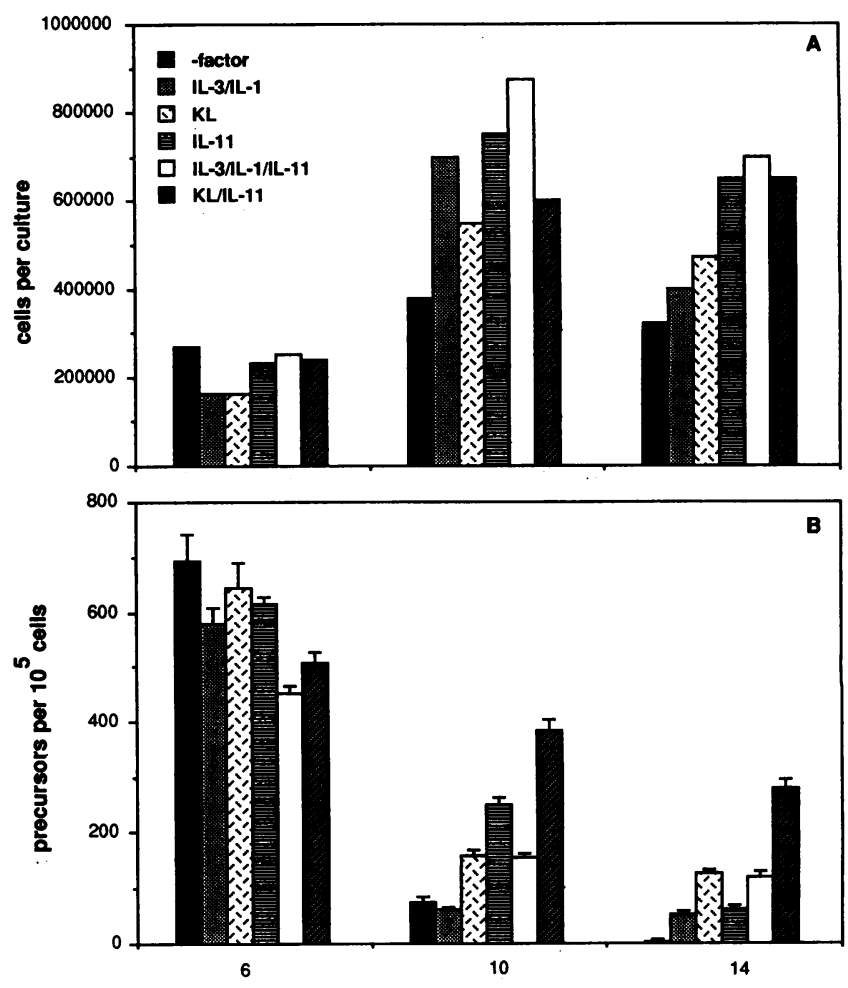

day of differentiation

FIG. 3. Effects of growth factors on hematopoietic development in the EBs. ES cells ( 500 per culture) were differentiated either in the absence of factor or in the presence of various factors as indicated. EBs were harvested at days 6,10, and 14 of differentiation, and the cells were dissociated and replated into secondary cultures which contained Epo, KL, IL-3, IL-1, and GM-CSF. (A) Total number of cells per culture; (B) precursor frequency. The following amounts of factors were used; IL-3, $2 \%$ conditioned medium (100 U); IL- $1 \alpha$, $1,000 \mathrm{U} / \mathrm{ml} ; \mathrm{KL}, 250 \mathrm{ng} / \mathrm{ml} ; \mathrm{IL}-11 ; 25 \mathrm{ng} / \mathrm{ml}$. The standard error of the mean of three cultures is indicated in panel B. The cellularity in panel A was calculated from a pool of three cultures.

growth factor BB, basic fibroblast growth factor, IGF-I, and IGF-II. These factors were chosen because they are known to be involved either directly or indirectly in the regulation of various stages of hematopoietic development $(23,24,47,51$, 65).

The data presented in Fig. 3 are limited to those factors which showed a reproducible effect on hematopoietic development in three independent experiments. IL-11 was the only factor tested that increased the number of EBs within the methylcellulose cultures. This increased number of EBs ( 25 to $50 \%$ more than in control cultures) led to an increase in cellularity that was most obvious at days 10 and 14 of differentiation (Fig. 3A). The addition of other factors such as KL and the combination of IL-3 and IL-1 resulted in only a modest increase in the size of the EBs but not to an increase in their number. None of the factors tested had a reproducible effect on the frequency of precursors found in the day $6 \mathrm{EBs}$ (Fig. 3B). Combined findings from eight independent experiments suggest that the earliest stages of hematopoietic development within the EBs are not dramatically influenced by the addition of any of these specific growth factors.

At later stages of development, various growth factors did exert an influence on precursor formation or survival. By 
day 10 of differentiation, EBs grown in the presence of $\mathrm{KL}$, IL-11, or a combination of KL plus IL-11 contained a higher frequency of precursors than did those differentiated in the presence of IL-3 plus IL-1 $\alpha$ or in the absence of additional factors (Fig. 3B). Under all conditions tested, EBs at this stage of development contained macrophage (M-CFC), erythroid (E-CFC), neutrophil/macrophage (GM-CFC), and pluripotential (mix-CFC) precursors.

By day 14 of differentiation, cultures with no factors had few precursor cells. EBs differentiated for 14 days in the presence of IL-3 plus IL-1 reproducibly contained more precursors than did those differentiated in the absence of factors. However, the large majority (50 to 60\%) of these were mast cell precursors (mast-CFC). Cultures containing KL had a consistently higher frequency of precursors than did those with IL-3 plus IL-1. Again a significant proportion (50 to $60 \%$ ) of these precursors were of the mast cell lineage, although M-CFC (20\%), E-CFC (10\%), mix-CFC (2\%), and GM-CFC (8\%) were also present. EBs that developed in the presence of IL-11 contained fewer mast cell precursors but did contain precursors for the other myeloid lineages. Interestingly, the highest frequency of precursors was detected in EBs differentiated in the presence of $\mathrm{KL}$ and IL-11; under these conditions, all myeloid precursors were present (Fig. 3B). The combination of IL-11 with IL-3 and IL-1 also stimulated more precursors than did either factor alone; however, the effect was not as dramatic as observed with the combination of KL and IL-11.

No other factors tested showed a reproducible effect on hematopoietic development, as determined by precursor frequency within the EBs. These results suggest that the factors tested do not influence the onset of hematopoiesis within the EBs but rather influence the survival and/or expansion of precursor cells once they develop. The factors most effective in this regard appear to be KL and IL-11.

Kinetics of specific lineage development. Our initial kinetics study indicated that erythroid precursors were predominant within the EBs at early stages of development, whereas precursors for other lineages developed at the later stages of differentiation. To accurately define the kinetics of development of the various hematopoietic lineages within these cultures, EBs differentiated in the presence of $\mathrm{KL}$ were harvested every 2 days, and the cells were dispersed and replated into secondary methylcellulose cultures containing different combinations of growth factors.

As observed in our previous kinetic study (Fig. 1), the first precursors to develop were Epo responsive and gave rise to small colonies (20 to 100 cells) of large nucleated erythroid cells (Fig. 4A, Ery/p:Epo). These precursors were detected routinely at day 5 of differentiation, reached maximum numbers at day 7 , and then declined to undetectable levels by day 10 . The small colonies derived from these erythroid precursors developed more efficiently in cultures containing PDS than in those with FCS. As early as day 5 of differentiation, another class of erythroid precursors could be detected. These cells required both KL plus Epo for growth and generated large colonies consisting of relatively small cells (Ery/d:KL/Epo). The number of these precursors increased by day 8 of differentiation, then remained constant, and finally began to decline by day 12 . These erythroid precursors respond much better to KL plus Epo than to IL-3, IL-1, and Epo (Ery/d:KL/Epo), a response that is different from that observed with erythroid precursors from adult marrow (see below). Macrophage precursors were the next population to develop, being present at day 6 of differentiation (Fig. 4B). Their number increased dramati- cally by day 8 and then declined over the next 6 days of differentiation. The best growth condition for these early macrophage precursors was M-CSF with IL-3 plus IL-1. Significantly fewer developed in the presence of IL-3 plus IL-1, and virtually none responded to M-CSF alone (not shown). Macrophage precursors which responded to IL-3 plus IL-1 were not present until day 8 of differentiation. Their number remained relatively constant over the next 6 days of differentiation, whereas those that responded to the combination of the three factors (M-CSF, IL-3, and IL-1) decreased significantly during this time.

Mix-CFC and GM-CFC precursors were present in maximum numbers by day 8 of differentiation (Fig. 4C). Their number declined gradually over the next 6 days of differentiation. Mast cell precursors were the last to develop, appearing within the EBs at day 10 of differentiation (Fig. 4D). As with the erythroid precursors, however, the earliest mast cell precursors responded preferentially to KL. IL-3responsive mast cell precursors were not present until day 14 of differentiation.

The size and the morphology of the cells in the early small erythroid colonies suggested that they could be primitive erythroid cells, whereas those in the larger colonies appear to be of the definitive lineage. To further investigate this possibility, pools of small Epo-stimulated colonies derived from day $6 \mathrm{EBs}$ were analyzed for the presence of both embryonic and adult globin. This globin pattern was compared with that found in the larger KL-plus-Epo-stimulated colonies derived from same EBs (day 6). The results shown in Fig. 5 clearly indicate that the cells within the small Epo-dependent colonies produce predominantly embryonictype globin, in ratios similar to that found in day 10 embryonic blood. In contrast, cells from the larger colonies stimulated with KL plus Epo produce only adult $\beta$-globin. These findings demonstrate that the small colonies do indeed consist of cell of the primitive erythroid lineage, whereas those in the large colonies appear to be of the definitive lineage.

The findings presented above indicate that the various precursor populations do develop within the EBs in a distinct kinetic pattern. In addition, they suggest that some of these early precursors, in particular those of the erythroid and mast cell lineages, have growth requirements that differ from those found in the adult animal. To determine whether these factor requirements were unique to ES-derived hematopoietic precursors or whether they reflected an embryonic pattern of responsiveness, we compared the KL and IL-3plus-IL-1 responsiveness of erythroid and mast cell precursors from yolk sac and fetal liver with that of adult bone marrow. Figure 6 shows that both the erythroid and mast cell precursors from day 10 yolk sac and day 12 fetal liver respond better to KL than to the combination of IL-3 and IL-1. In fact, none of the mast cell precursors in the yolk sac and very few of those in the fetal liver responded to IL-3 plus IL-1. In contrast, both the erythroid and mast cell precursors in the bone marrow respond slightly better to IL-3 plus IL-1 than to $\mathrm{KL}$. The fetal liver response to $\mathrm{KL}$ appears to be a direct effect of the ligand on the precursor cell, as the number of colonies observed is directly proportional to the number of cells plated (data not shown). Together, these findings suggest that the growth factor responsiveness of the ES-derived precursors is similar to that of the precursors found in the yolk sac and the fetal liver. 


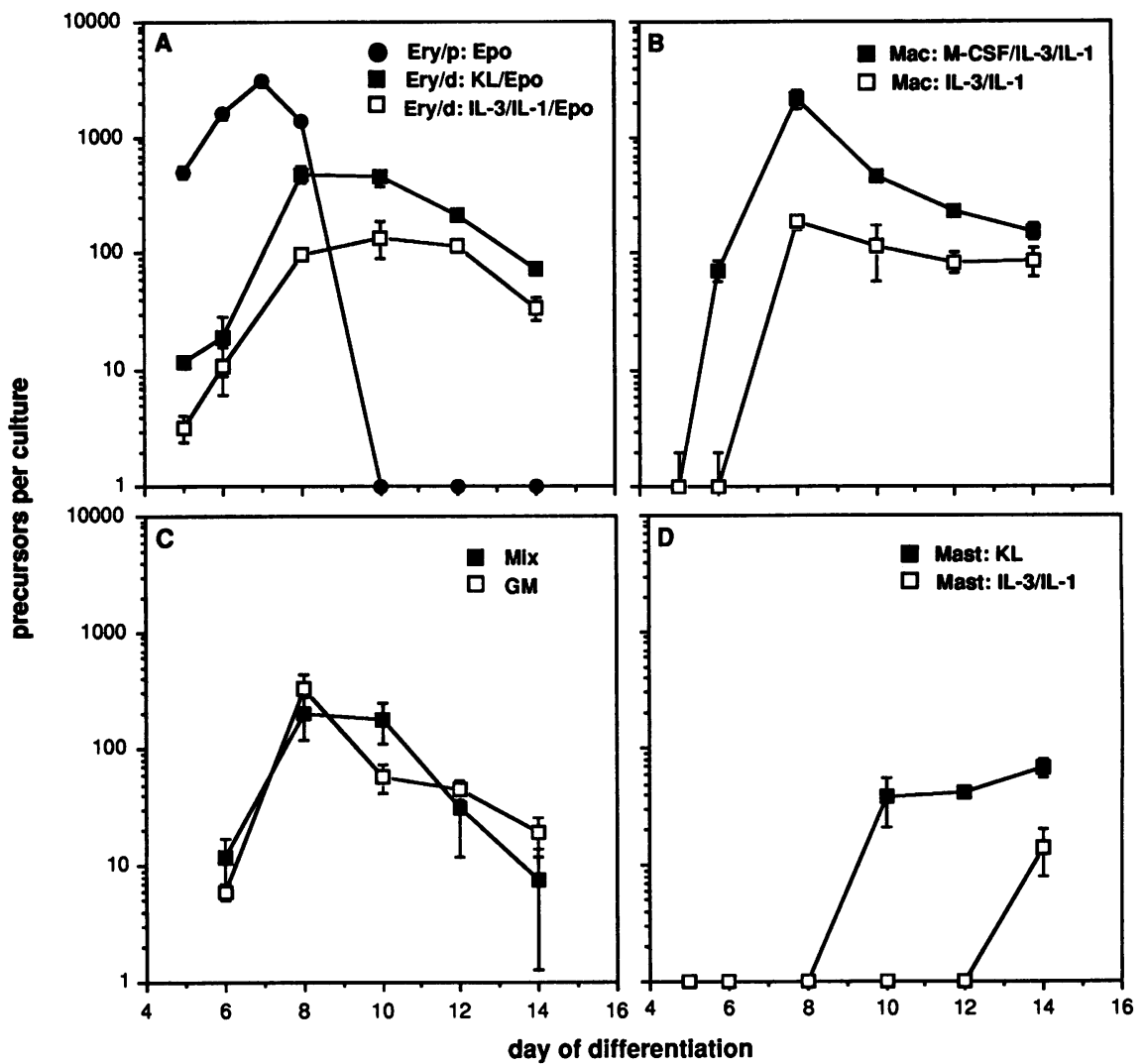

FIG. 4. Kinetics of lineage development within the EBs. ES cells ( 500 per culture) were plated into methylcellulose cultures containing $\mathrm{KL}$. The resulting EBs were harvested at various days following the initiation of differentiation and assayed for precursor content. The following growth factor combinations were used for the detection of different types of precursors: (A) Epo alone, Epo and KL, or Epo, IL-3, and IL-1 for erythroid precursors; (B) IL-3 and IL-1 or M-CSF, IL-3, and IL-1 for macrophages (mac); (C) GM-CSF, KL, IL-3, and IL-1 for bipotential neutrophil/macrophage precursors and KL, IL-3, IL-1, Epo, GM-CSF, and M-CSF for mix-CFC; (D) either KL or IL-3 and IL-1 for mast cell precursors. Ery/p are those precursors which generated small colonies of large nucleated erythroid cells and were scored in cultures containing only Epo; Ery/d generated large colonies of small erythroid cells and were scored in cultures containing either KL and Epo or IL-3, IL-1, and Epo, as indicated. Mix precursors are those which generated multilineage colonies consisting of erythroid cells plus at least two other lineages. Bars indicate the standard deviations of the means of three cultures.

\section{DISCUSSION}

In this report, we show that ES cells will efficiently and reproducibly generate EBs containing hematopoietic cells in methylcellulose cultures. The proportion of EBs which contain hematopoietic cells $(>85 \%)$ as well as the frequency of precursors (up to 1\%) found within these EBs are significantly higher than previously reported $(10,56,61)$. The underlying reason for these differences is not known, but it could be related to the amount as well as to the type of serum used in the differentiation cultures.

Molecular analysis of hematopoietic development. The predictable onset of hematopoiesis in the EBs within 4 to 5 days of differentiation has allowed us to analyze the expression pattern of various classes of genes prior to and during the establishment of the hematopoietic system. From these findings, it is possible to begin to define the sequence of molecular events which leads to the development of the hematopoietic system within the EBs. In addition, a comparison of the expression pattern of these genes in the developing embryo with that in the EB allowed us to address the question of whether the normal sequence of events involved in establishing the hematopoeitic system in vivo are also occurring in culture.

One of the most convincing findings suggesting that the early events in culture are similar to those in vivo was the demonstration that both the collagen $\alpha$ IV and Brachyrury genes, markers for primitive endoderm and mesoderm, respectively $(2,29,62)$, were expressed in the embryo and the EBs prior to the onset of hematopoiesis. Thus, the events leading from ectoderm to the formation of endoderm and mesoderm thought to be essential in the formation of the hematopoietic system in the embryo appear to be ongoing within the EBs in culture. One unexpected finding was that the AFP gene, a marker for visceral endoderm, was not expressed until day 6 of EB differentiation, whereas it was present early in the embryo. This finding suggests that AFP-producing visceral endoderm is not present within the early EBs and thus not required for the primary events involved in the establishment of the hematopoietic system. In more recent studies, we have detected significant amounts of AFP RNA in EBs differentiated for longer periods of time ( $>8$ days) (61a), a finding consistent with previous studies (17).

The expression pattern of a number of the other genes analyzed is consistent with their involvement in early hematopoietic development. For instance, GATA-1, a gene known to be involved in development of the erythroid lineage $(52,57)$, is expressed within the EBs and the devel- 


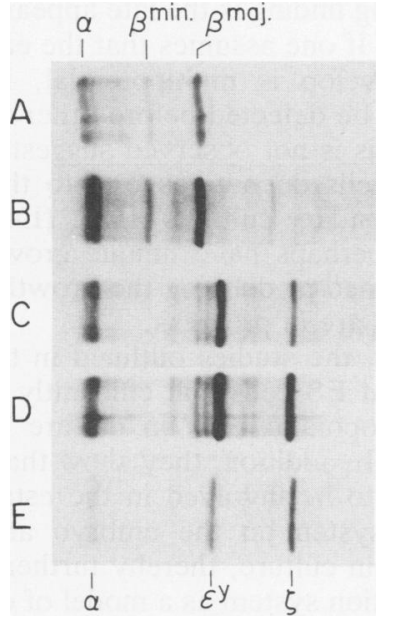

FIG. 5. Globin analysis of EB-derived erythroid colonies. Shown is globin chain isoelectric focusing of adult blood (lane A) and embryonic blood (lane E) and of erythroid colony lysates from the methylcellulose cultures (lanes B to D). Lane B is the lysate from the large KL-Epo-responsive colonies, whereas lanes $C$ and $D$ are the lysates from the small Epo-responsive colonies. Lane $\mathrm{C}$ is a pool of picked colonies, whereas lane D represents the contents of an entire methylcellulose culture stimulated with Epo only. Note that large colonies generated in the presence of $\mathrm{KL}$ (lane B) synthesize mostly adult $\beta$-globin, whereas the small colonies (lanes $C$ and $D)$ produce mostly embryonic globins $\{\beta$-like $[\varepsilon y(y)]$ and $\alpha$-like $[\zeta(\mathbf{x})]\}$. $\beta^{\text {min. }}, \beta$ minor globin; $\beta^{\text {maj. }}, \beta$ major globin.

oping egg cylinder just prior to and during the development of the earliest erythroid precursors. Within the developing embryo, GATA-1 expression precedes globin ( $\beta \mathrm{H} 1)$ expression by approximately $24 \mathrm{~h}$, whereas in the EBs, the genes are expressed on the same day of differentiation. This difference might reflect a difference in the kinetics of development between the EB and the embryo. Thus, GATA-1 might be expressed only $12 \mathrm{~h}$ before $\beta \mathrm{H} 1$ within the EBs, a difference that would not be detected in our analysis. In several studies, we have found low levels of GATA-1specific message in the EBs within $72 \mathrm{~h}$ of differentiation (data not shown), suggesting that GATA-1 could be expressed somewhat earlier than $\beta H 1$.

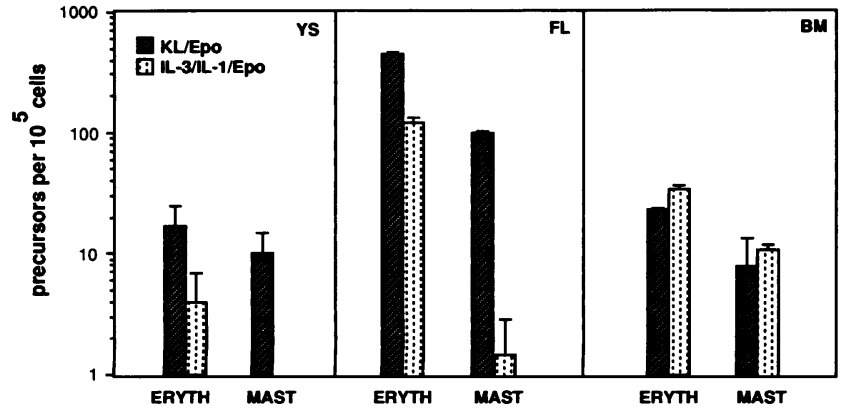

FIG. 6. Responses of yolk sac-, fetal liver-, and bone marrowderived erythroid (ERYTH) and mast cell (MAST) precursors to different growth factors. Yolk sac (YS) cells were harvested from embryos at day 10 of gestation, and fetal liver (FL) cells were obtained from day 12 embryos. The fetal tissues as well as the adult bone marrow (BM) were obtained from Swiss Webster outbred animals. The results shown are the means \pm standard errors of two separate experiments.
The early expression of c-myb is somewhat surprising, as gene inactivation studies have indicated that it is not required in the embryo until fetal liver hematopoietic development (45). The fact that it is expressed in the EBs within 48 $h$ of differentiation suggests that either the events in vitro occur much faster than in the embryo or that the gene is expressed early but not required until later stages of development. Differentiation studies with ES cells in which both alleles of the c-myb gene have been inactivated would allow us to determine its exact role in the development of the hematopoeitic system in culture. The early expression of vav and SCL within the developing EBs is also consistent with their involvement in the early stages of hematopoietic development. One unexpected finding was the lack of expression of $v a v$ in the early embryo. Although the reason for this is currently not clear, it could be an indication that the early cell population which expresses vav is more abundant in the EBs than in the embryo at days 6.5 to 8.5 of gestation.

The hematopoietic system develops within the EBs in the absence of growth factors with the exception of those present in PDS or FCS or those produced within the EBs. The findings that Epo- and Epo receptor-specific RNA are present within the EBs at all stages of differentiation is consistent with the observations from previous studies (28, 56) and suggests that this ligand-receptor interaction could be involved in the establishment of the early erythroid lineage. A more defined role for Epo in the development of the early hematopoietic system must await studies with ES cells in which the Epo or Epo receptor gene has been inactivated. KL and c-kit are also expressed relatively early within the EBs. However, the significant upregulation of both genes between days 5 and 7 of differentiation suggests that $\mathrm{KL}$ and c-kit play a role following the initiation of hematopoiesis. This interpretation would be consistent with the in vivo studies with $W$ and $S l$ mice which indicate that $\mathrm{KL}$ and c-kit are not required for the onset of yolk sac hematopoiesis but rather are involved in the development of the fetal liver hematopoietic system $(31,48)$. The late expression of M-CSF (day 6) and its receptor, c-fms (day 6; not shown), and the absence of IL-3 expression suggest that neither of these factors plays any role in the establishment of the hematopoietic system.

Effects of exogenous factors on ES-EB hematopoiesis. Our inability to significantly alter the development of the early hematopoietic system within the EBs by the addition of a large variety of known factors is striking and suggests that the early stages of hematopoiesis could be regulated by novel receptor-ligand interactions. Once the precursors are generated, however, they appear to be susceptible to the influence of some exogenously added known factors. Of a large groups of factors analyzed, only KL, IL-11, and the combination of IL-3 and IL-1 exhibited any significant effect on the developing precursors. IL-11 was originally identified as a stromal cell-derived factor that stimulated the growth of a plasmacytoma cell line and, together with IL-3, the growth of megakaryocyte colonies (51). Its role in embryonic and fetal hematopoiesis is unknown. Here we show for the first time that it can enhance the number of hematopoietic precursors that are generated within day 10 and day 14 EBs. Perhaps more impressive is the combined effect of IL-11 and $\mathrm{KL}$, which increases both the frequency and total number of ES-derived hematopoietic precursors at days 10 and 14 of differentiation. Synergy between KL and IL-11 has been recently document by Quesniaux et al. (53), who showed that the combination of these factors together with Epo stimulated the development of large erythroid colonies from 
normal marrow precursors. In addition, this combination of factors also stimulated primitive hematopoietic cells (premix-CFC) to generate mix-CFC in culture. It is possible that IL-11 acts on relatively early cells of the hematopoietic lineage and thus is able to influence hematopoietic development within the EBs. Unfortunately, the sequence of mouse IL-11 is currently unknown, and thus we were unable to determine whether the gene is expressed within the EBs. One additional unexpected finding was that IL-11 signifcantly increased the number of EBs that developed within the cultures, indicating that it has some influence on undifferentiated ES cells. To date, IL-11 is the only factor that we have tested that reproducibly increased the plating efficiency of ES cells in methylcellulose cultures without inhibiting differentiation. Whether IL-11 can promote the growth of undifferentiated ES cells in combination with other factors such as $\operatorname{LIF}(58,63)$ remains to be determined. The factor analysis described here differs from that of Burkert et al. (10), who found that the addition of Epo increased erythropoiesis in the differentiation cultures. However, their analysis was based on the observation of visible hematopoiesis within the primary EBs (i.e., EBs becoming red) and not on the number of precursors that developed. In our previous report (61), we also observed more extensive erythropoiesis in cultures containing IL-3, IL-1, and Epo. This type of analysis can be misleading, as in many instances EBs that contain large numbers of precursors have no obvious signs of hematopoietic activity.

Comparison of precursor formation in both EBs and embryos. Certain aspects of the kinetics of lineage development observed within the EBs (Fig. 4) shows remarkable similarities to that observed in the developing embryo. Perhaps the most striking example is the early development of the primitive erythroid precursors. Several characteristics of these EB-derived erythroid precursors are identical to those of a population of erythroid precursors found in the early yolk sac $(66,68)$. For instance, both populations respond to Epo and generate small colonies of large nucleated erythroid cells which produce embryonic globin. In addition, in both the yolk sac and the EBs, this population is transient, appearing very early and then disappearing very rapidly. The reason for the rapid decline in this population is not known, but it may be related to a change in the environment in both the yolk sac and the EBs. The fact that the early onset of hematopoiesis in the EBs and yolk sac are similar suggests that the mechanism regulating these early developmental stages in culture and in the embryo are the same.

Shortly after the appearance of the first primitive erythroid precursors, precursors of the definitive lineage can be detected, demonstrating that early in hematopoietic development within the EBs, these two erythroid populations appear as separate lineages. Whether they arise from a common erythroid-committed cell remains to be determined. One unique aspect of these early definitive erythroid precursors is they respond to $\mathrm{KL}$ and Epo much better than to IL-3, IL-1, and Epo. A similar situation is observed with the earliest developing mast cells precursors found in the EBs at day 10 of differentiation. Erythroid and mast cell precursors from both yolk sac and fetal liver, but not the bone marrow, also respond better to $\mathrm{KL}$ and Epo (only $\mathrm{KL}$ for mast) than to the combination of IL-3, IL-1, and Epo (only IL-3 for mast), again indicating that hematopoietic development within the EBs in culture parallels that observed in the developing embryo. In addition, these findings indicate that the growth factor responsiveness of the embryonic and fetal precursors differs from those found in the adult animal.
One interesting finding is the late appearance of mix-CFC within the EBs. If one assumes that the earliest hematopoietic cell to develop is multipotential, then multilineage colonies should be detected before other types of colonies. The fact that this is not observed suggests that the earliest hematopoietic cells do not respond to the growth factors used in the secondary cultures (IL-3, IL-1, KL, GM-CSF, and Epo) and perhaps have unique growth requirements. Experiments aimed at defining the growth requirements of these early cells are in progress.

In conclusion, the studies outlined in this report clearly demonstrate that ES cells will efficiently and reproducibly generate hematopoietic cells in culture in a well-defined kinetic pattern. In addition, they show that the sequence of events thought to be involved in the establishment of the hematopoietic system in the embryo are also occurring within the EBs in culture, thereby further validating the in vitro differentiation system as a model of early hematopoiesis. The reproducible onset of hematopoiesis within the EBs described here will now allow us to identify and characterize the earliest embryonic hematopoietic cells as well as to define the molecular events involved in their establishment.

\section{ACKNOWLEDGMENTS}

We thank Britt Johansson for excellent technical assistance; Susan Carson, Beat Imhof, Ton Rolink, Patricia Ruiz, Kyunghee Choi, and Meri Firpo for helpful discussions and critical reading of the manuscript; Christel Schmidt of R. Kemler's laboratory for assistance in microdissection; and Rudolpho Albano and Jim Smith for communicating data concerning the expression pattern of activin $\beta_{B}$ in ES cells before publication.

This work was supported in part by grant RO1 DK43285-01 from the National Institutes of Health. The Basel Institute for Immunology was founded and is supported by F. Hoffmann-La Roche and Co. Ltd., Basel, Switzerland.

\section{REFERENCES}

1. Adams, J. M., H. Houston, J. Allen, T. Lints, and R. Harvey. 1992. The hematopoietically expressed vav proto-oncogene shares homology with the dbl-gtp exchange factor, the bcr gene and yeast gene (cdc24) involved in cytoskeletal organization. Oncogene 7:611-618.

2. Adamson, E. D., and S. E. Ayers. 1979. The localization and synthesis of some collagen types in developing mouse embryos. Cell 16:953-965.

3. Albano, R. M., N. Groome, and J. C. Smith. Activins are expressed in preimplantation mouse embryos and in ES and EC cells and are regulated on their differentiation. Development, in press.

4. Azoulay, M., C. G. Webb, and L. Sachs. 1987. Control of hematopoietic cell growth regulators during mouse fetal development. Mol. Cell. Biol. 7:3361-3364.

5. Beddington, R. 1987. Mammalian development-a practical approach, p. 43-69. IRL Press, Oxford.

6. Begley, C. G., P. D. Aplan, S. Denning, B. F. Haynes, T. A. Waldmann, and I. R. Kirsch. 1989. The gene SCL is expressed during early hematopoiesis and encodes a differentiation-related DNA-binding motif. Proc. Natl. Acad. Sci. USA 86:1012810132.

7. Begley, C. G., J. Visvader, A. R. Green, P. D. Aplan, D. Metcalf, I. R. Kirsch, and N. M. Gough. 1991. Molecular cloning and chromosomal localization of the murine homolog of the human helix-loop-helix gene SCL. Proc. Natl. Acad. Sci. USA 88:869873.

8. Boltz, N. G., C. Wiltschke, C. Holzinger, A. Fellinger, O. Scheiner, A. Gessl, and O. Forster. 1987. Differentiation of rat bone marrow cells into macrophages under the influence of mouse L929 cell supernatant. J. Leukocyte Biol. 41:83-91.

9. Brotherton, T. W., D. H. Chui, J. Gauldie, and M. Patterson. 1979. Hemoglobin ontogeny during normal mouse fetal devel- 
opment. Proc. Natl. Acad. Sci. USA 76:2853-2857.

10. Burkert, U., R. T. von Ruden, and E. F. Wagner. 1991. Early fetal hematopoietic development from in vitro differentiated embryonic stem cells. New Biol. 3:698-708.

11. Chelly, J., J. P. Concordet, J. C. Kaplan, and A. Kahn. 1989. Illegitimate transcription: transcription of any gene in any cell type. Proc. Natl. Acad. Sci. USA 86:2617-2621.

12. Chelly, J., J. C. Kaplan, P. Maire, S. Gautron, and A. Kahn. 1988. Transcription of the dystrophin gene in human muscle and non-muscle tissue. Nature (London) 333:858-860.

13. Chomczynski, P., and N. Sacchi. 1987. Single-step method of RNA isolation by acid guanidinium thiocyanate-phenol-chloroform extraction. Anal. Biochem. 162:156-159.

14. Choppin, J., N. Casadevall, C. Lacombe, F. Wendling, E. Goldwasser, R. Berger, P. Tambourin, and B. Varet. 1985. Production of erythropoietin by cloned malignant murine erythroid cells. Exp. Hematol. 13:610-615.

15. Cline, M. J., and M. A. Moore. 1972. Embryonic origin of the mouse macrophage. Blood 39:842-849.

16. Coppola, J., S. Bryant, T. Koda, D. Conway, and M. Barbacid. 1991. Mechanism of activation of the vav protooncogene. Cell Growth Differ. 2:95-105.

17. Doetschman, T. C., H. Eistetter, M. Katz, W. Schmidt, and R. Kemler. 1985. The in vitro development of blastocyst-derived embryonic stem cell lines: formation of visceral yolk sac, blood islands and myocardium. J. Embryol. Exp. Morphol. 87:2745.

18. Dyson, P. J., F. Poirier, and R. J. Watson. 1989. Expression of c-myb in embryonal carcinoma cells and embryonal stem cells. Differentiation 42:24-27.

19. Dziadek, M., and E. Adamson. 1978. Localization and synthesis of alphafoetoprotein in post-implantation mouse embryos. $\mathrm{J}$. Embryol. Exp. Morphol. 8:152-160.

20. Dziadek, M. A., and G. K. Andrews. 1983. Tissue specificity of alpha-fetoprotein messenger RNA expression during mouse embryogenesis. EMBO J. 2:549-554.

21. Evans, M. J., and M. Kaufman. 1981. Pluripotential cells grown directly from mouse embryos. Cancer Surv. 2:185-208.

22. Flanagan, J. G., D. C. Chan, and P. Leder. 1991. Transmembrane form of the kit ligand growth factor is determined by alternative splicing and is missing in the Sld mutant. Cell 64:1025-1035.

23. Froesch, E. R., C. Schmid, J. Schwander, and J. Zapf. 1985. Actions of insulin-like growth factors. Annu. Rev. Physiol. 47:443-467.

24. Gabbianelli, M., M. Sargiacomo, E. Pelosi, U. Testa, G. Isacchi, and C. Peschle. 1990. "Pure" human hematopoietic progenitors: permissive action of basic fibroblast growth factor. Science 249:1561-1564.

25. Gorman, D. M., N. Itoh, T. Kitamura, J. Schreurs, S. Yonehara, I. Yahara, K.-I. Arai, and A. Miyajima. 1990. Cloning and expression of a gene encoding an interleukin 3 receptor-like protein: identification of another member of the cytokine receptor gene family. Proc. Natl. Acad. Sci. USA 87:5459-5463.

26. Haar, J. L., and G. A. Ackerman. 1971. Ultrastructural changes in mouse yolk sac associated with the initiation of vitelline circulation. Anat. Rec. 170:437-455.

27. Hara, T., and A. Miyajima. 1992. Two distinct functional high affinity receptors for mouse interleukin-3 (IL-3). EMBO J. 11:1875-1884.

28. Heberlein, C., K. D. Fischer, M. Stofiel, J. Nowock, A. Ford, U. Tessmer, and C. Stocking. 1992. The gene for erythropoietin receptor is expressed in multipotential hematopoietic and embryonal stem cells: evidence for differentiation stage-specific regulation. Mol. Cell. Biol. 12:1815-1826.

29. Herrmann, B. G., S. Labeit, A. Poustka, T. R. King, and H. Lehrach. 1990. Cloning of the $\mathrm{T}$ gene required in mesoderm formation in the mouse. Nature (London) 343:617-622.

30. Hogan, B. L., A. Taylor, and E. Adamson. 1981. Cell interactions modulate embryonal carcinoma cell differentiation into parietal or visceral endoderm. Nature (London) 291:235-237.

31. Ikuta, K., and I. L. Weissman. 1992. Evidence that hematopoietic stem cells express mouse c-kit but do not depend on steel factor for their generation. Proc. Natl. Acad. Sci. USA 89:15021506.

32. Itoh, N., S. Yonehara, J. Schreurs, D. M. Gorman, K. Maruyama, A. Ishii, I. Yahara, K.-I. Arai, and A. Miyajima. 1990. Cloning of an interleukin-3 receptor gene: a member of a distinct receptor gene family. Science 247:324-327.

33. Johnson, G. R., and D. C. Barker. 1985. Erythroid progenitor cells and stimulating factors during murine embryonic and fetal development. Exp. Hematol. 13:200-208.

34. Johnson, G. R., and D. Metcalf. 1978. Sources and nature of granulocyte-macrophage colony stimulating factor in fetal mice. Exp. Hematol. 6:327-335.

35. Karasuyama, H., and F. Melchers. 1988. Establishment of mouse cell lines which constitutively secrete large quantities of interleukin 2, 3, 4, or 5 using modified cDNA expression vectors. Eur. J. Immunol. 18:97-104.

36. Katzav, S., Z. D. Martin, and M. Barbacid. 1989. vav, a novel human oncogene derived from a locus ubiquitously expressed in hematopoietic cells. EMBO J. 8:2283-2290.

37. Ko, L. J., M. Yamamoto, M. W. Leonard, K. M. George, P. Ting, and J. D. Engel. 1991. Murine and human T-lymphocyte GATA-3 factors mediate transcription through a cis-regulatory element within the human $\mathrm{T}$-cell receptor delta gene enhancer. EMBO J. 10:1187-1192.

38. Labastie, M. C., J. P. Thiery, and D. N. LeDouarin. 1984. Mouse yolk sac and intraembryonic tissues produce factors able to elicit differentiation of erythroid burst-forming units and colonyforming units, respectively. Proc. Natl. Acad. Sci. USA 81: 1453-1456.

39. Lindenbaum, M. H., and F. Grosveld. 1990. An in vitro globin gene switching model based on differentiated embryonic stem cells. Genes Dev. 4:2075-2085.

40. Luscher, B., and R. N. Eisenman. 1990. New light on Myc and Myb. Part II. Myb. Genes Dev. 4:2235-2241.

41. Matsui, Y., K. M. Zsebo, and B. L. Hogan. 1990. Embryonic expression of a hematopoietic growth factor encoded by the $\mathrm{S} 1$ locus and the ligand for c-kit. Nature (London) 347:667-669.

42. Miura, Y., and F. H. Wilt. 1969. Tissue interaction and the formation of the first erythroblasts of the chick embryo.. Dev. Biol. 19:201-211.

43. Moore, M. A., and D. Metcalf. 1970. Ontogeny of the haemopoietic system: yolk sac origin of in vivo and in vitro colony forming cells in the developing mouse embryo. Br. J. Haematol. 18:279296.

44. Mortensen, R. M., D. A. Conner, S. Chao, A. A. T. Geisterferlowrance, and J. G. Seidman. 1992. Production of homozygous mutant embryonic stem cells with a single targeting construct. Mol. Cell. Biol. 12:2391-2395.

45. Mucenski, M. L., K. McLain, A. B. Kier, S. H. Swerdlow, C. M. Schreiner, T. A. Miller, D. W. Pietryga, W. J. Scott, and S. S. Potter. 1991. A functional c-myb gene is required for normal murine fetal hepatic hematopoiesis. Cell 65:677-689.

46. Murre, C., P. S. McCaw, H. Vaessin, M. Cady, L. Y. Jan, Y. N. Jan, C. v. Cabrera, J. N. Buskin, S. D. Hauschka, A. B. Lassar, H. Weintraub, and D. Baltimore. 1989. Interactions between heterologous helix-loop-helix proteins generate complexes that bind specifically to a common DNA sequence. Cell 58:537-544.

47. Nicola, N. A. 1989. Hemopoietic cell growth factors and their receptors. Annu. Rev. Biochem. 58:45-77.

48. Nocka, K., S. Majumder, B. Chabot, P. Ray, M. Cervone, A. Bernstein, and P. Besmer. 1989. Expression of c-kit gene products in known cellular targets of $\mathrm{W}$ mutations in normal and $\mathrm{W}$ mutant mice-evidence for an impaired c-kit kinase in mutant mice. Genes Dev. 3:816-826.

49. Oohira, A., T. N. Wight, J. McPherson, and P. Bornstein. 1982. Biochemical and ultrastructural studies of proteoheparan sulfates synthesized by PYS-2, a basement membrane-producing cell line. J. Cell Biol. 92:357-367.

50. Papayannopoulou, T., S. Kurachi, M. Brice, B. Nakamoto, and G. Stamtoyannopoulos. 1981. Asynchronous synthesis of $\mathrm{HbF}$ and $\mathrm{HbA}$ during erythroblast maturation. II. Studies of $\mathrm{G} \gamma, \mathrm{A} \gamma$, and $\beta$ chain synthesis in individual erythroid clones from neonatal and adult BFU-E cultures. Blood 57:531-536. 
51. Paul, S. R., F. Bennett, J. A. Calvetti, K. Kelleher, C. R. Wood, R. M. O'Hara, Jr., A. C. Leary, B. Sibley, S. C. Clark, A. A. Williams, and Y.-C. Yang. 1990. Molecular cloning of a cDNA encoding interleukin 11, a stromal cell-derived lymphopoietic and hematopoietic cytokine. Proc. Natl. Acad. Sci. USA 87: 7512-7516.

52. Pevny, L., M. C. Simon, E. Robertson, W. H. Klein, S. F. Tsai, V. D'Agati, S. H. Orkin, and F. Costantini. 1991. Erythroid differentiation in chimaeric mice blocked by a targeted mutation in the gene for transcription factor GATA-1. Nature (London) 349:257-260.

53. Quesniaux, V. F. J., S. C. Clark, K. Turner, and B. Fagg. 1992 Interleukin 11 stimulates multiple phases of erythropoiesis in vitro. Blood 80:1218-1223.

54. Righetti, P. G., E. Gianazza, A. M. Gianni, P. Comi, B. Giglioni, S. Ottolenghi, C. Sechi, and M. Rossi-Bernard. 1979. Human globin chain separation by isoelectric focusing. J. Biochem. Biophys. Methods 1:45-55.

55. Robertson, E., A. Bradley, M. Kuehn, and M. Evans. 1986. Germ-line transmission of genes introduced into cultured pluripotential cells by retroviral vector. Nature (London) 323:445448.

56. Schmitt, R. M., E. Bruyns, and H. R. Snodgrass. 1991. Hematopoietic development of embryonic stem cells in vitro: cytokine and receptor gene expression. Genes Dev. 5:728-740.

57. Simon, M. C., L. Pevny, M. V. Wiles, G. Keller, F. Costantini, and S. H. Orkin. 1992. Rescue of the block to erythropoiesis in murine ES cells lacking a functional GATA-1 gene: analysis of a transcription factor in a developmental program. Nature Genet. 1:92-98.

58. Smith, A. G., J. K. Heath, D. D. Donaldson, G. G. Wong, J. Moreau, M. Stahl, and D. Rogers. 1988. Inhibition of pluripotential stem cell differentiation by purified polypeptides. Nature (London) 336:688-690.

59. Whitelaw, E., S. F. Tsai, P. Hogben, and S. H. Orkin. 1990 Regulated expression of globin chains and the erythroid transcription factor GATA-1 during erythropoiesis in the developing mouse. Mol. Cell. Biol. 10:6596-6606.

60. Wiles, M. V. 1992. Embryonic stem cell differentiation in vitro. Methods Enzymol., in press.

61. Wiles, M. V., and G. Keller. 1991. Multiple hematopoietic lineages develop from embryonic stem (ES) cells in culture.
Development 111:259-267.

61a.Wiles, M. V., and C. Schmidt. Unpublished data.

62. Wilkinson, D. G., S. Bhatt, and B. G. Herrmann. 1990. Expression pattern of the mouse $\mathrm{T}$ gene and its role in mesoderm formation. Nature (London) 343:657-659.

63. Williams, R. L., D. J. Hilton, S. Pease, T. A. Wilson, C. L. Stewart, D. P. Gearing, E. F. Wagner, D. Metcalf, N. A. Nicola, and N. M. Gough. 1988. Myeloid leukemia inhibitory factor maintains the developmental potential of embryonic stem cells. Nature (London) 336:684-686.

64. Wilt, F. H. 1965. Erythropoiesis in the chick embryo: the role of the endoderm. Science 147:1588-1590.

65. Witte, O. N. 1990. Steel locus defines new multipotent growth factor. Cell 63:5-6.

66. Wong, P. M., S. W. Chung, C. H. Chui, and C. J. Eaves. 1986. Properties of the earliest clonogenic hemopoietic precursors to appear in the developing murine yolk sac. Proc. Natl. Acad. Sci. USA 83:3851-3854.

67. Wong, P. M., S. W. Chung, C. J. Eaves, and D. H. Chui. 1985. Ontogeny of the mouse hemopoietic system. Prog. Clin. Biol. Res. 193:17-28.

68. Wong, P. M., S. W. Chung, S. M. Reicheld, and D. H. Chui. 1986. Hemoglobin switching during murine embryonic development: evidence for two populations of embryonic erythropoietic progenitor cells. Blood 67:716-721.

69. Ymer, S. W., Q. Tucker, C. J. Sanderson, A. J. Hapel, H. D. Campbell, and I. G. Young. 1985. Constitutive synthesis of interleukin-3 by leukaemia cell line WEHI-3B is due to retroviral insertion near the gene. Nature (London) 317:255-258.

70. Zhang, X. K., Z. Wang, A. Lee, D. P. Huang, and J. F. Chiu. 1988. Differential expression of cellular oncogenes during rat liver development. Cancer Lett. 41:147-155.

71. Zon, L. I., C. Mather, S. Burgess, M. E. Bolce, R. M. Harland, and S. H. Orkin. 1991. Expression of GATA-binding proteins during embryonic development in Xenopus laevis. Proc. Natl Acad. Sci. USA 88:10642-10646.

72. Zsebo, K. M., D. A. Williams, E. N. Geissler, V. C. Broudy, F. H. Martin, H. L. Atkins, R. Y. Hsu, N. C. Birkett, K. H. Okino, D. C. Murdock, F. W. Jacobsen, K. E. Langley, K. A. Smith, T. Takeishi, B. M. Cattanach, S. J. Galli, and S. V. Suggs. 1990. Stem factor is encoded at the S1 locus of the mouse and is the ligand for the c-kit tyrosine kinase receptor. Cell 63:213-224. 